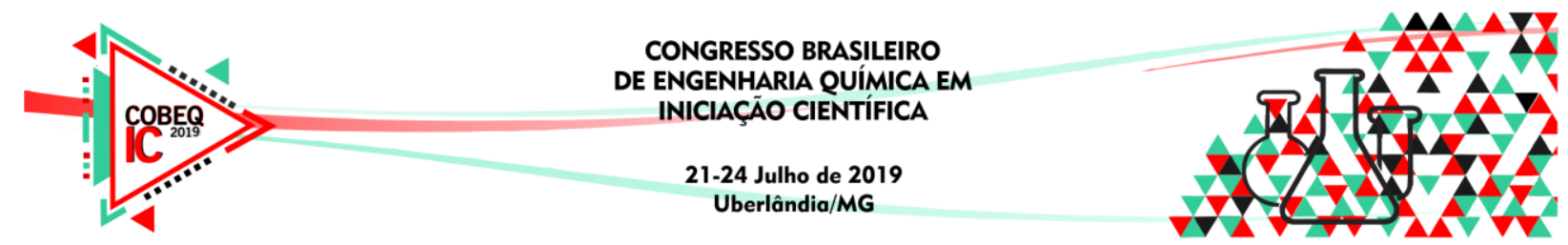

\title{
DEGRADAÇÃO EM REATOR MECANICAMENTE AGITADO DE EFLUENTE DE AZUL DE METILENO UTILIZANDO PERSULFATO DE SÓDIO ATIVADO POR HIDRÓXIDO DE FERRO SUPORTADO EM DIATOMITA
}

\author{
J. C. R. CARVALHO ${ }^{1}$, M. A. SILVA ${ }^{1}$, J. D. B. COSTA-FILHO ${ }^{1}$, D. F. S. SOUZA ${ }^{1}$ \\ ${ }^{1}$ Universidade Federal do Rio Grande do Norte, Departamento de Engenharia Química \\ E-mail para contato: jjulia.rribeiro@gmail.com
}

\begin{abstract}
RESUMO - O processo oxidativo avançado (POA) representa um vantajoso método na degradação de corantes. Neste processo, os contaminantes são mineralizados a compostos inertes através de rápidas reações químicas de oxidação. Entretanto, o sucesso do método está atrelado a escolha apropriada do agente oxidante. Os oxidantes a base persulfato tem recebido atenção, principalmente, por não sofrer significativas alterações de $\mathrm{pH}$. Este trabalho tem como objetivo, estudar a degradação do corante azul de metileno em um reator em batelada com agitação mecânica. Um planejamento experimental foi idealizado para avaliar o efeito da massa de catalisador e persulfato no tratamento do contaminante em questão. Os resultados obtidos mostraram que em todos os ensaios realizados, houve uma degradação superior a 95\% do corante.
\end{abstract}

\section{INTRODUÇÃO}

Estima-se que mais de 700.000 toneladas de corantes sintéticos sejam produzidas anualmente no mundo. $\mathrm{Na}$ indústria têxtil, devido a ineficiência do processo de tingimento, 200.000 toneladas são perdidas anualmente, ao fim do processo, o equivalente a aproximadamente 30\% da produção, CHEQUER et al., (2013). O efluente gerado por esse tipo de indústria apresenta elevada carga de compostos químicos orgânicos, dando a este uma característica de difícil degradação e elevada toxicidade, DILARRI et al., (2016). Os corantes, mesmo em menor concentração que outros compostos, geram uma acentuada coloração. Este efeito pode ocasionar uma redução do oxigênio dissolvido e a interferência nos processos fotossintéticos naturais do corpo d'água, devido a não penetração de luz solar e acarretando prejuízos a toda biota aquática, (LALNUNHLIMI; KRISHNASWAMY, 2016). No Brasil, a Portaria $n^{\circ} 2.914 / 2011$ do Ministério da Saúde exige que o valor máximo para cor aparente do efluente seja de 15 uH (unidade Hazen) e, dessa forma, estudos em tratamentos objetivando minimizar os impactos ambientais e atender as regulamentações se fazem necessários, CONAMA, (2011).

Adsorção é um dos processos de tratamento frequentemente utilizados para efluentes das indústrias têxteis e consiste em um fenômeno físico que acontece nas interfaces do sistema fluído-sólido, no qual o corante fica retido no adsorvente, BABEL, (2003). Contudo, nesse processo, o contaminante é apenas transferido da fase líquida para a sólida e não degradado como em tratamentos biológicos e oxidativos. Já os processos biológicos não são 


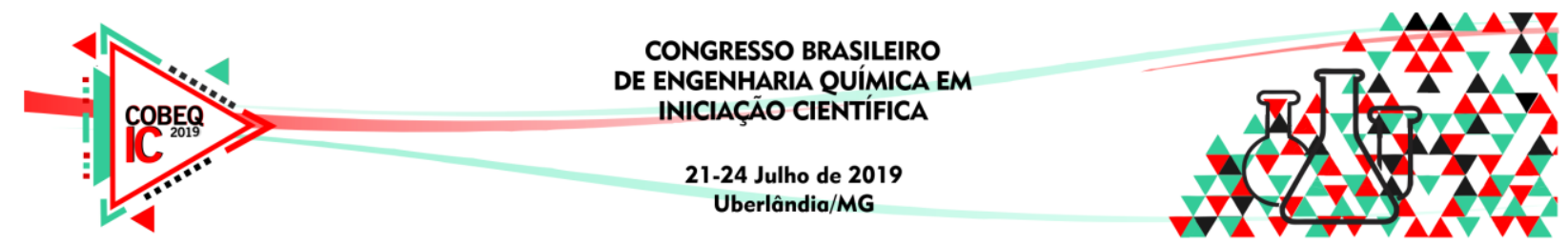

eficientes na degradação de corantes sintéticos, principalmente porque as complexas estruturas aromáticas do contaminante tornam o meio recalcitrante, FEWSON, (1998).

Os processos oxidativos avançados (POAs) tem ganhado destaque, pois são capazes transformar uma variedade de poluentes em compostos inertes, em um curto intervalo de tempo. A essência do método reside em criar condições adequadas para promover a degradação dos contaminantes reduzindo-os a formas menos nocivas ou até mesmo, a completa mineralização por meio de reações químicas. A associação entre catalisadores a base de íons ferrosos e um forte agente oxidante provou degradar com sucesso hidrocarbonetos, pesticidas, fármacos, ARAÚJO, Karla Santos, (2016), corantes, HUNG et al., (2016), entre outras substâncias. Entretanto, para que a ativação seja eficiente se faz necessário a acidificação do meio, tonando esse processo desvantajoso. Uma alternativa é suportar o íon ferro no interior de um material poroso. Neste caso, o oxidante é ativado sem a necessidade de um ajuste no pH, SILVA-RACKOV et al., (2017).

Os principais oxidantes utilizados nos POAs são: peróxido de hidrogênio, persulfato, permanganato e ozônio. Dentre estes, o persulfato tem chamado atenção, sobretudo pelo prolongado tempo de meia-vida, podendo se dispersar por maiores distâncias. Além disso, não sofre significativas influências de alterações de $\mathrm{pH}$ e, após a reação, os produtos são transformados em íons sulfato, ambientalmente amigáveis, ZHANG et al., (2014). Ante ao exposto, este trabalho tem como objetivo principal estudar a degradação do azul de metileno utilizando persulfato de sódio ativado por catalisador sintetizado conforme descrito por SilvaRackov et al. (2017) em reator mecanicamente agitado.

\section{METODOLOGIA}

A fim de avaliar a influência do persulfato de sódio e o catalisador na descolorização do efluente de azul de metileno através do processo oxidativo avançado, foi idealizado um planejamento fatorial $2^{2}+3$ pontos centrais, conforme descrito na Tabela 1 .

Tabela $1-$ Planejamento fatorial $2^{2}+3$ pontos centrais.

\begin{tabular}{ccccc}
\hline & \multicolumn{2}{c}{ Valores normalizado } & \multicolumn{2}{c}{ Valores absoluto } \\
\cline { 2 - 5 } Ensaio & $\begin{array}{c}\text { Massa de } \\
\text { catalisador }(\mathrm{g})\end{array}$ & $\begin{array}{c}\text { Massa de } \\
\text { persulfato }(\mathrm{g})\end{array}$ & $\begin{array}{c}\text { Massa de } \\
\text { catalisador (g) }\end{array}$ & $\begin{array}{c}\text { Massa de } \\
\text { persulfato }(\mathrm{g})\end{array}$ \\
\hline 1 & -1 & -1 & 0,5 & 0,24 \\
2 & +1 & -1 & 1,5 & 0,24 \\
3 & -1 & +1 & 0,5 & 1,67 \\
4 & +1 & +1 & 1,5 & 1,67 \\
5 & 0 & 0 & 1,0 & 0,96 \\
6 & 0 & 0 & 1,0 & 0,96 \\
7 & 0 & 0 & 1,0 & 0,96 \\
\hline
\end{tabular}

Os experimentos foram realizados em reator em batelada com agitador mecânico operando a uma rotação de $500 \mathrm{rpm}$ a temperatura ambiente. Foram utilizados $250 \mathrm{~mL}$ de efluente sintético de azul de metileno com uma concentração de $200 \mathrm{mg} . \mathrm{L}^{-1}$ juntamente com a massa de oxidante e catalisador segundo o planejamento. O tempo reacional total foi 20 


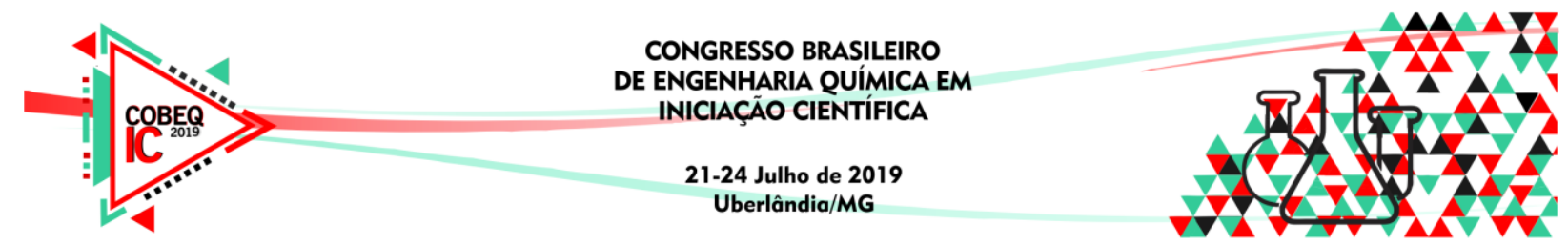

minutos, uma vez que a reação de degradação de azul de metileno através de POA ocorre rapidamente HUNG et al., (2016). As amostras foram retiradas nos intervalos de 1, 3, 5, 7, 9, 11,15 e 20 minutos. A concentração do corante nas amostras foi analisada usando um espectrômetro de massa. Objetivando averiguar a influência da adsorção do corante no material catalítico, bem como a fotodegradação do azul de metileno, foi realizado um ensaio controle no qual $1,5 \mathrm{~g}$ de catalisador foi adicionado ao reator com agitação mecânica a um volume de $250 \mathrm{~mL}$ de efluente. Amostras foram retiradas nos tempos de 10 e 20 minutos e analisadas.

\section{RESULTADOS E DISCUSSÕES}

O resultado do ensaio controle mostrou que não há influência do processo de adsorção e a fotodegradação nas condições operacionais utilizadas, uma vez que a concentração após 10 e 20 minutos não mostrou variações significativas (Figura 1).

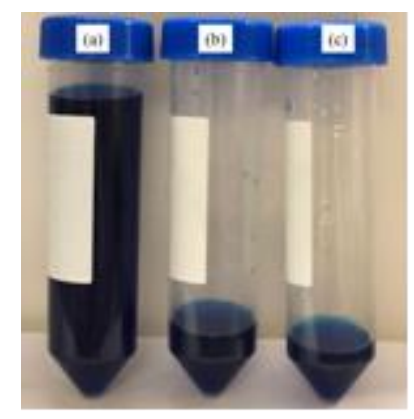

Figura 1 - Ensaio controle (adsorção e fotodegradação) do azul de metileno

Poucos segundos após a adição da mistura persulfato de sódio e catalisador ao reator previamente preenchido com o efluente sintético de azul de metileno, observou-se uma mudança de coloração do meio para a cor púrpura. Essa alteração ocorre devido a formação de flocos não estáveis. Um comportamento semelhante foi notado por Ghauch et al. (2012) em reação de degradação de azul de metileno por persulfato de sódio ativado termicamente, em que também ocorre a formação de um sólido roxo que difere do azul de metileno quanto a forma e a composição. Diante desta situação, as amostras retiradas do reator foram filtradas a fim de evitar a influência deste material na análise espectrofotométrica. A Figura 2 mostra o efluente em cada etapa do processo oxidativo.

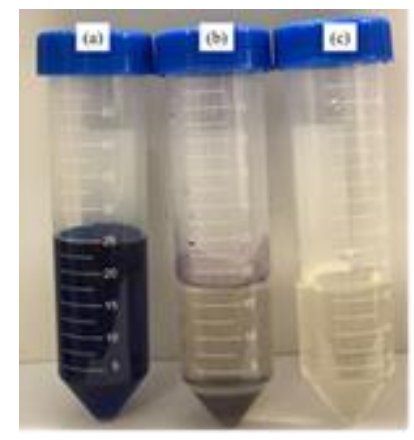

Figura 2 - Efluente: (a) pré-tratamento; (b) pós-tratamento não filtrado; (c) póstratamento filtrado. 


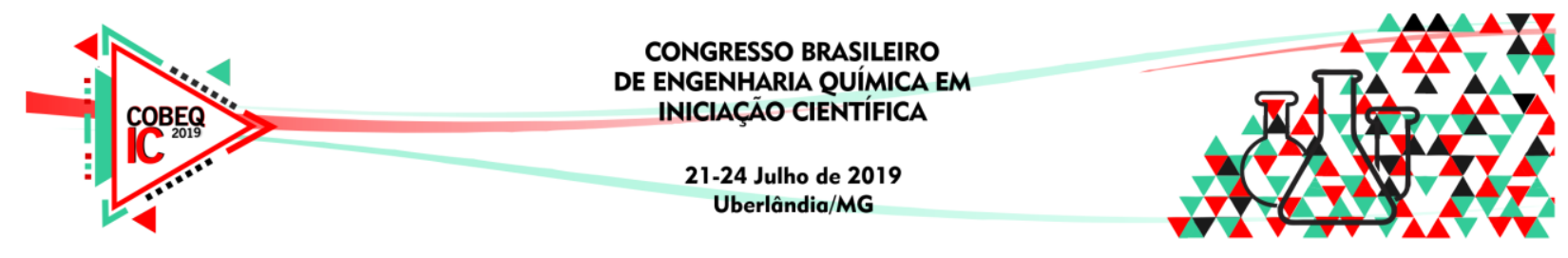

A primeira amostra retirada do reator em um tempo reacional de 1 minuto revelou um decaimento brusco na concentração de azul de metileno, valores abaixo de $5 \mathrm{mg}$. $\mathrm{L}^{-1}$ foram observados para todas as condições experimentais. Hung et al. (2016) ao utilizar persulfato ativado por óxido de ferro para degradação de azul de metileno notaram que os minutos inicias da reação de oxidação são responsáveis pelo maior decréscimo da concentração do corante. A Figura 3 mostra o decaimento da concentração do corante azul de metileno durante 20 minutos reacionais para uma mesma massa de catalisador $(3 \mathrm{a}-0,5 \mathrm{~g}$ e $3 \mathrm{~b}-1,5 \mathrm{~g})$ e diferentes concentrações de persulfato de sódio.
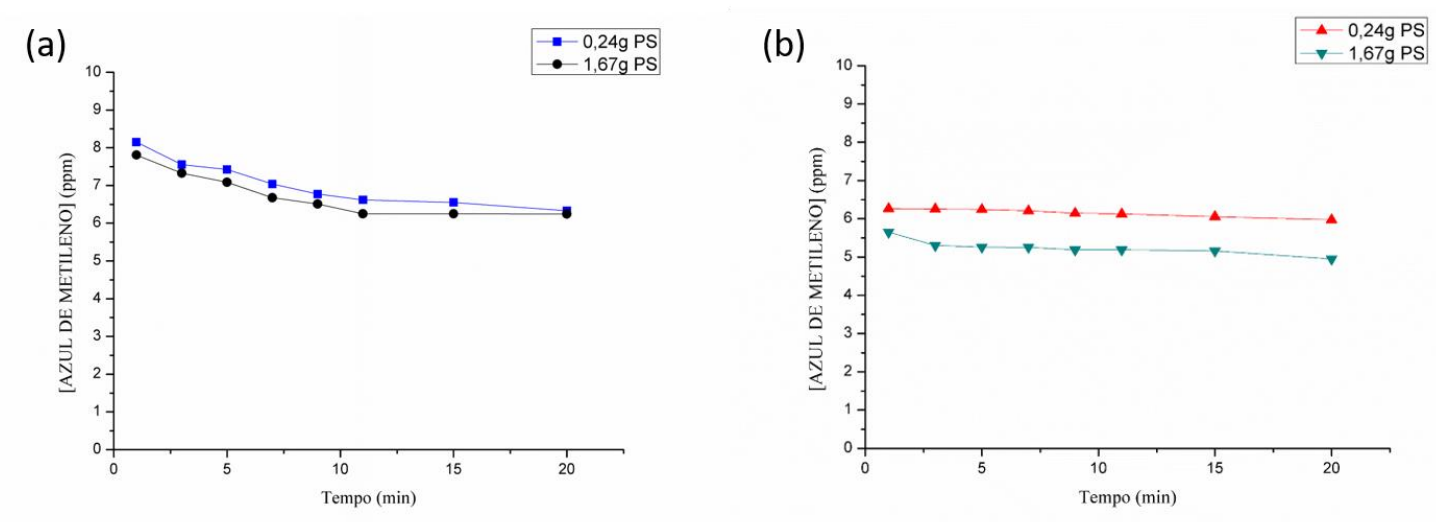

Figura 3 - Concentração de azul de metileno no tempo para diferentes concentrações de persulfato de sódio e para massa de catalisador de: (a) $0,5 \mathrm{~g}$; (b) $1,5 \mathrm{~g}$.

A análise dos gráficos acima mostra que os valores obtidos são justificados pela literatura e confirmam a rapidez da reação Hung et al., (2016). É evidente que o aumento na concentração de oxidante irá proporcionar uma maior degradação do corante, o que pode ser atribuído ao aumento dos radicais sulfato na solução. Contudo, quando o oxidante é mantido constante e a massa de catalisador é variada (Figura 4), observa-se que a maior concentração de material catalítico proporciona o decaimento mais rápido da concentração do corante.

(a)

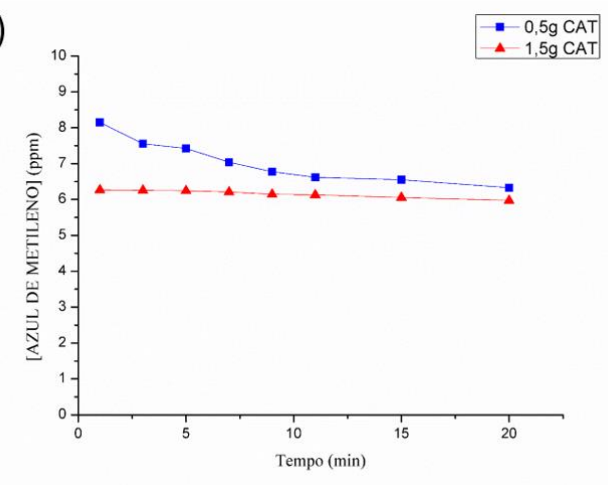

(b)

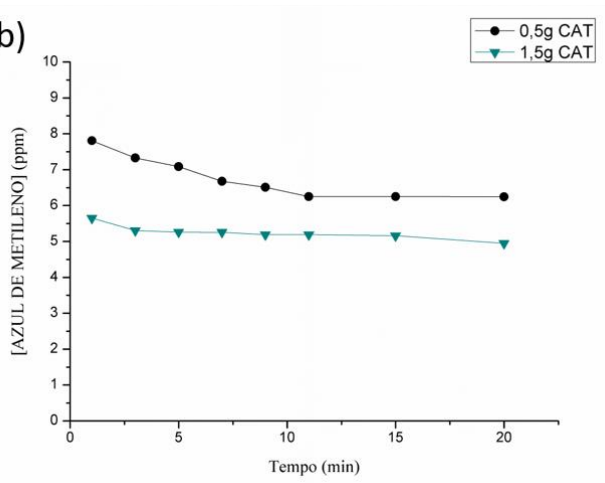

Figura 4 - Concentração de azul de metileno no tempo para diferentes massas de catalisador e para massa de persulfato de sódio de: (a) 0,24g; (b) 1,67g.

Com o aumento na concentração do catalítico no efluente, mais íons sulfato são convertidos em radicais sulfato, aumentando o potencial de oxidação e, dessa forma, a 


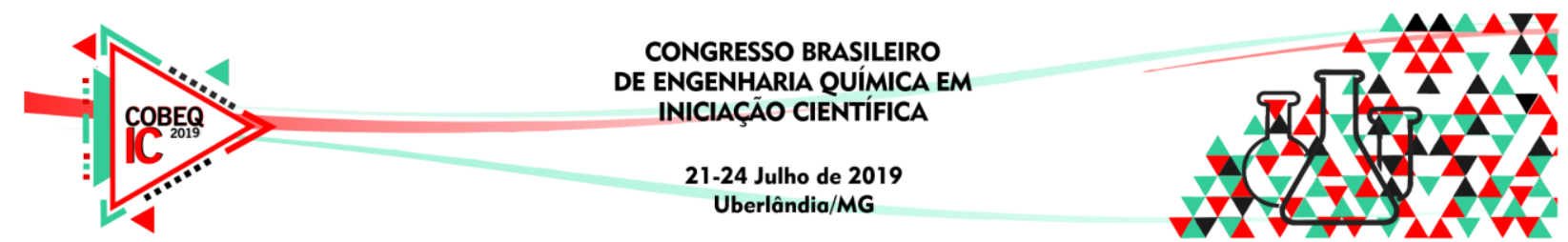

degradação do azul de metileno é favorecida. Avaliando a influência do catalisador e do oxidante no decaimento da concentração de azul de metileno nota-se que, nos minutos iniciais, a massa do material catalítico é mais significativa que a concentração do persulfato de sódio, de modo que maiores concentrações de catalisador proporcionaram maior degradação do corante quando comparado a maiores concentrações do persulfato.

O valor mínimo da concentração do azul de metileno foi alcançado em menos de 1 minuto de reação. A Figura 5 mostra a superfície de resposta obtida do planejamento.

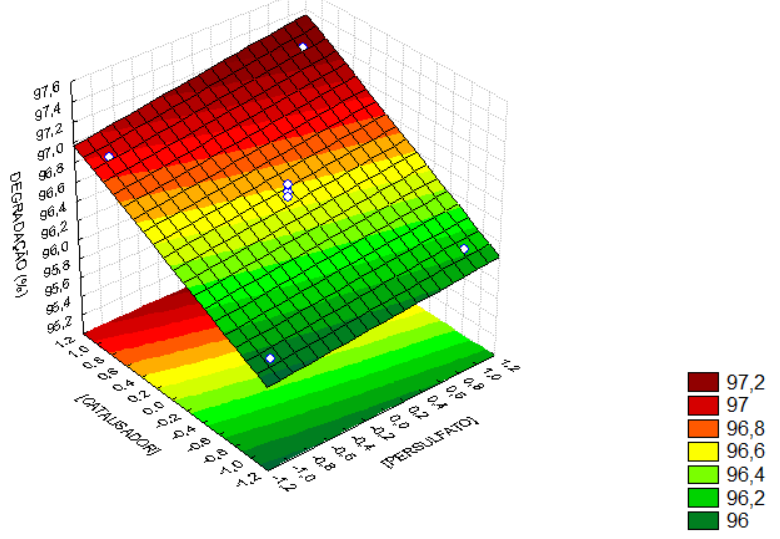

Figura 5 - Superfície de resposta do planejamento.

Observa-se que os maiores valores de degradação são apresentados para maiores concentrações de persulfato e catalisador, contudo, é válido salientar que todos os resultados obtidos estão acima de $95 \%$ de degradação do corante. O diagrama de Pareto (Figura 6) revela que a variável significativa para o processo foi a massa de catalisador, estando coerente com o discutido anteriormente.

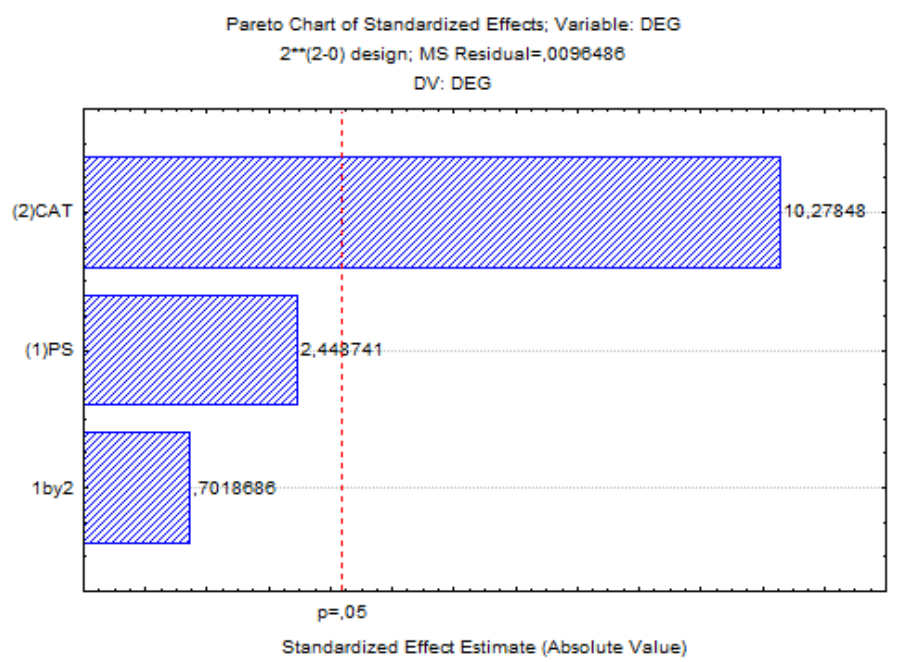

Figura 6 - Diagrama de Pareto para concentração de persulfato e concentração de catalisador. 


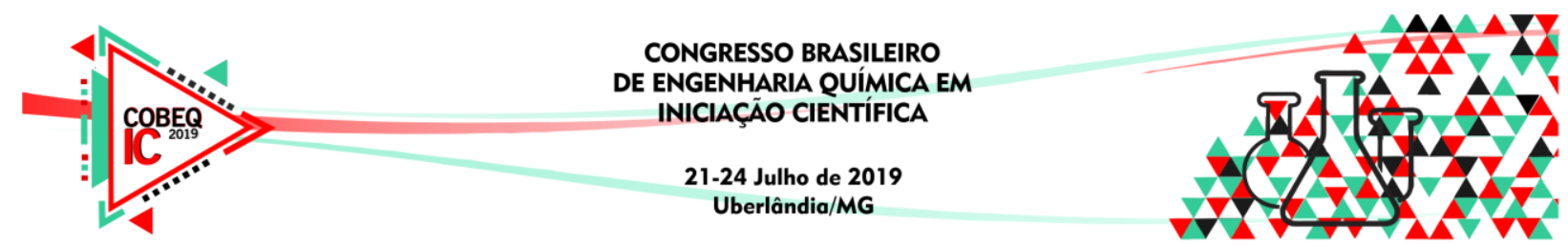

\section{CONCLUSÃO}

O método oxidativo avançado se mostrou bastante eficaz quanto à degradação do azul de metileno, onde tal procedimento conseguiu uma degradação acima de $95 \%$ em aproximadamente 1 minuto de reação, esse resultado se mostrou bastante satisfatório se comparado com o de outros autores que realizaram um procedimento similar.

\section{REFERENCIAS}

ARAÚJO, Karla Santos, fundamentals and applications in wastewater treatment. Ambiente e Agua, v. 11, n. 2, p.387, 15 (2016).

BABEL, S. Low-cost adsorbents for heavy metals uptake from contaminated water, Hazardous Materials, v. 97, p.219-243, 28 (2003).

BRASIL. Ministério do Meio Ambiente. Conselho Nacional do Meio Ambiente - CONAMA. n. 430, de 13 (2011).

CHEQUER, F.M. DRUMOND, Textile Dyes: Dyeing Process and Environmental Impact. Eco-friendly Textile Dyeing And Finishing, p.151-176, 16 (2013).

DILARRI, Guilherme, Removal of Dye Toxicity from an Aqueous Solution Using an Industrial Strain of Saccharomyces Cerevisiae. Water, Air, \& Soil Pollution, v. 227, n. 8, p.269, 14 (2016).

GHAUCH, Antoine, Methylene blue discoloration by heated persulfate in aqueous solution. Chemical Engineering Journal, v. 213, p.259-271, 2012.

FEWSON, C. A. Biodegradation of xenobiotic and other persistent compounds. Trends in Biotechnology, v. 6, p. 148-153, 1998.

HUNG, Chang-mao, Decolorization of Methylene Blue by Persulfate Activated with $\mathrm{FeO}$ Magnetic Particles. Water Environment Research, v. 88, n. 8, p.675-686, 1 (2016).

LALNUNHLIMI, S.; KRISHNASWAMY, V. Decolorization of azo dyes by moderately alkaliphilic bacterial consortium. Brazilian Journal of Microbiology, v. 47, p. 39-46, 2016.

SILVA-RACKOV, C. K. O.; AGUIAR, L. G.; SOUZA, A. R.; SILVA, S. S. O.; CÂMARA, A. G.; VIANNA, M. M. G. R.; FOLETTO, E. L.; NASCIMENTO, C. A. O.; CHIAVONEFILHO, O. Remediation of Phenanthrene-Contaminated Soil by Persulfate Activated with FeModified Diatomite, Water, Air \& Soil Pollution, v. 228, p. 271, 2017.

ZHANG Q, CHEN J, DAI C. Degradation of carbamazepine and toxicity evaluation using the UV/persulfate process in aqueous solution. J Chem Technol Biotechnol., 2014. 